\title{
MPPT in Battery Charging for PV Applications
}

\author{
Joseph Brian D'Souza ${ }^{1}$, Bharathi A Rao ${ }^{2}$ \\ PG student, E\&E Department, SJEC, Mangaluru, India ${ }^{1}$ \\ Assistant Professor, E\&E Department, SJEC, Mangaluru, India ${ }^{2}$
}

\begin{abstract}
This paper deals with the implementation of maximum power point tracker (MPPT) for solar panel along with safe battery charging algorithm for lead acid battery. This is a stand-alone system with incremental conductance MPPT algorithm and can be used for stand-alone application. Single ended primary inductor converter (SEPIC) is used to match the impedance of solar panel and battery to deliver maximum power. Voltage and current from the solar panel is sensed and duty cycle of gating signal is varied accordingly by the algorithm to attain maximum power transfer.
\end{abstract}

Keywords: MPPT, Incremental Conductance, Battery Changing Algorithm, SEPIC.

\section{INTRODUCTION}

In the recent world the use of non-renewable source of energy has drastically increased. These non-renewable sources like gas, oil, coal, nuclear energy etc. has results in the pollution resulting global warming, depletion of Ozone layer etc. now it is time until it's too late to reduce the use of non-renewable source of energy and focus on renewable sources which are clean form of energy. To meet the raising power demand, photovoltaic technology which is strongly developed can be used, were a part of sun light is transformed into electricity. This paper is basically based on two principle topics, the MPPT algorithm using a SPEIC converter and safe charging of lead-acid battery algorithm. Thus this paper shows the work on MPPT algorithm for photovoltaic stand-alone system aiming to improve the power transfer from solar panel. This MPPT algorithm is used in one of the charging stages of safe charging algorithm of lead acid battery. One of the simple MPPT algorithms is perturbation and observation method but this algorithm isn't effective for rapidly changing environmental conditions. Looking at the drawbacks of $\mathrm{P} \& \mathrm{O}$ algorithm incremental conductance algorithm was developed. It is based on the fact that increasing panel conductance is equal to the instantaneous panel conductance at maximum power point. Different stages in the safe battery charging of lead acid battery are also explained.

\section{INCREMENTAL CONDUCTANCE}

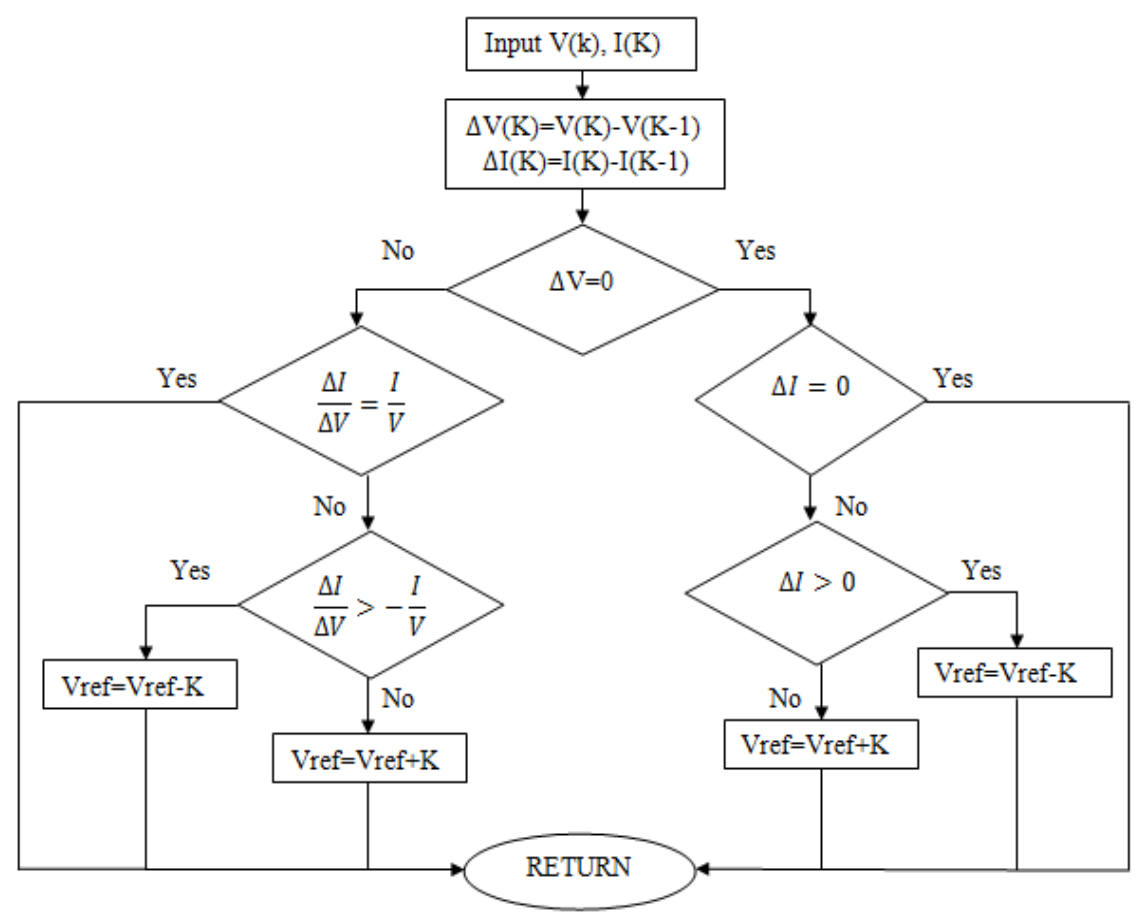

Fig.1: Flow Chart of Incremental Conductance. 
Incremental conductance is based on the fact that when incremental conductance is equal to the instantaneous conductance of solar panel MPP (maximum power point) is achieved. If the incremental conductance value is greater than instantaneous conductance that means the operating point is in the left side to the MPP, if the incremental conductance value is less than instantaneous conductance this implies the operation point is in the right side to the MPP. If both the values are equal then the point is at MPP. The oscillations around the maximum power point found in $\mathrm{P} \& \mathrm{O}$ algorithm is overcome by this algorithm.

Flow chat of incremental conductance algorithm is shown in fig.1. It can be seen that incremental conductance and instantaneous conductance of the solar panel is compared and maximum power point is traced. $\mathrm{K}$ is a constant known as increment size; the fast tracking of MPP is dependent on size of the K. If K is large, tracking of MPP is faster. But instead of operating at MPP it will oscillate around MPP and if K is small tracking of MPP is slower, but it works at MPP after MPP is traced.

\section{BATTERY CHARGING ALGORITHM}

For long life of the battery it is necessary to charge the battery using safe battery charging algorithm, in which it is charged within the safe limits, it would be possible to charge the battery in faster possible way as power generated by the solar panel is limited. This algorithm is based on the four charging stages of the lead acid battery as recommended by the some of the battery manufacturers. The four stages of the battery are (a) trickle charge (b) bulk charge (c) over charge and (d) float charge. Fig.2 Show the curves of current and voltage.

\section{$1^{\text {ST }}$ STAGE: TRICKLE CHARGE}

In this stage the battery voltage has come down below the critical discharge value VCHGENB. To get the battery voltage up to VCHGENB, the battery needs to be charged by a small charge current defined by ITC for several hours. Once the battery voltage builds up to VCHGENB the battery charging stage is passed on to next stage.

\section{$2^{\mathrm{ND}}$ STAGE: BULK CHARGE}

In this stage the battery can be charged by applying maximum rated current $\mathrm{I}_{\mathrm{BUCK}} \mathrm{O}$ the battery as specified by the manufacturers. This current is applied till the battery voltage builds up to maximum value of overcharge voltage VOC.

\section{$3^{\text {RD }}$ STAGE: OVER CHARGE}

In this stage the battery is fully charged. The current starts to fall slowly and when the current falls below the value $\mathrm{I}_{\mathrm{OCT}}$, the next stage is executed.

\section{$4^{\text {TH }}$ STAGE: FLOAT CHARGE}

In this stage the constant voltage $\mathrm{V}_{\mathrm{FLOAT}}$ is applied to the battery to avoid auto discharge. During discharge if the battery voltage falls below $0.9 \mathrm{~V}_{\text {FLOAT }}$ the control algorithm will execute $2^{\text {nd }}$ stage. If not the battery continues to discharge and may go below critical discharge value. In this algorithm 1st stage is not implemented, instead dropping of battery voltage below critical discharge voltage is avoided by disconnecting load from the battery by the control algorithm. 4th stage isn't implemented instead from 3rd stage directly 2 nd stage is executed if the battery voltage goes below over charge voltage $\mathrm{V}_{\mathrm{OC}}$.

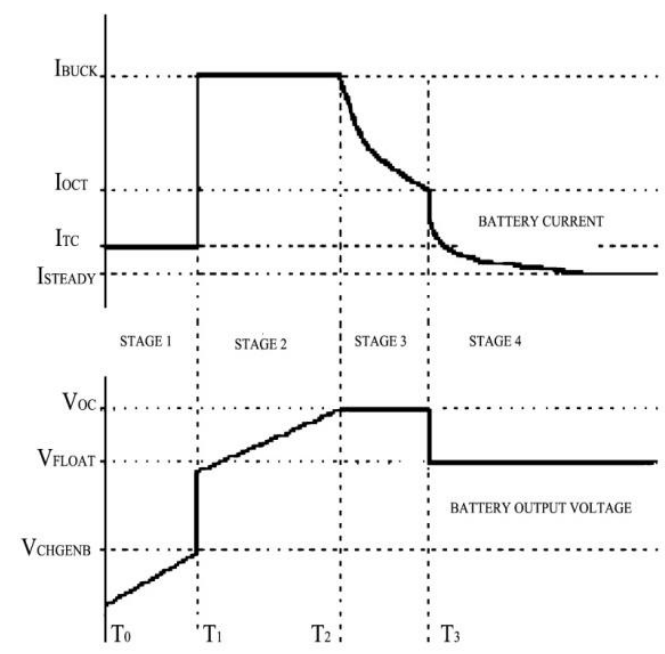

Figure 2: Current and voltage curves in the four stages of battery charging. 
NMAM Institute of Technology, Nitte

Vol. 3, Special Issue 2, Month 2016

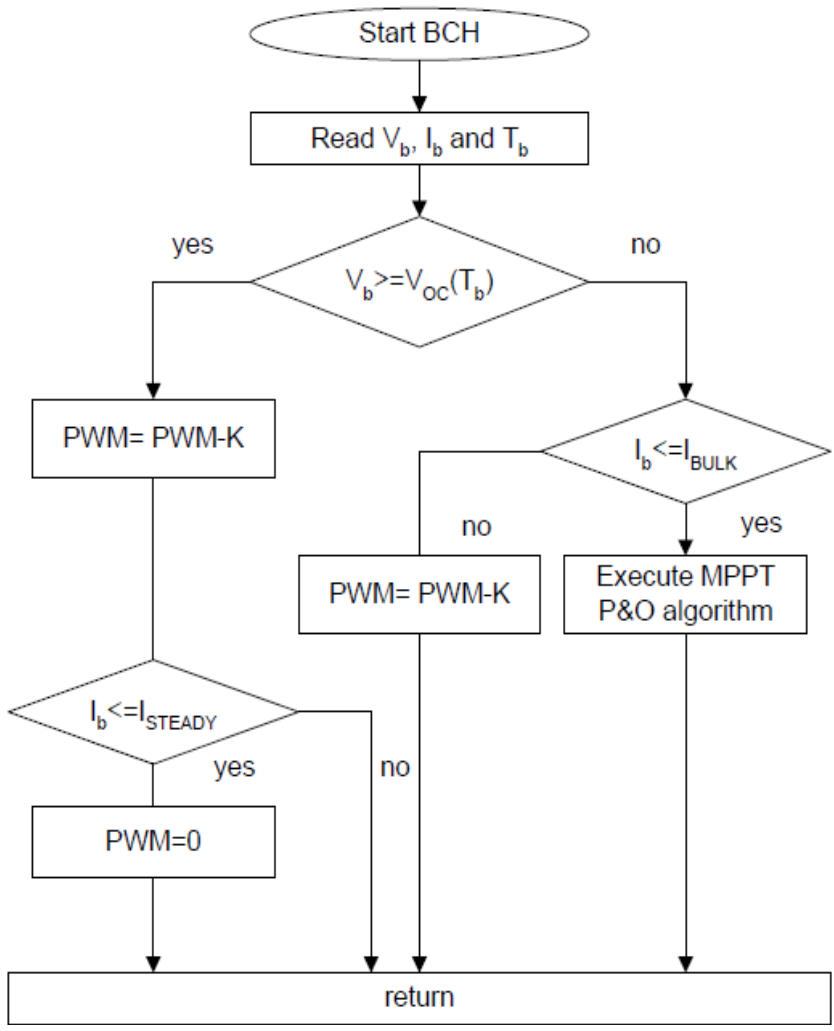

Fig.3: Battery charging algorithm.

\section{CIRCUIT DIAGRAM}

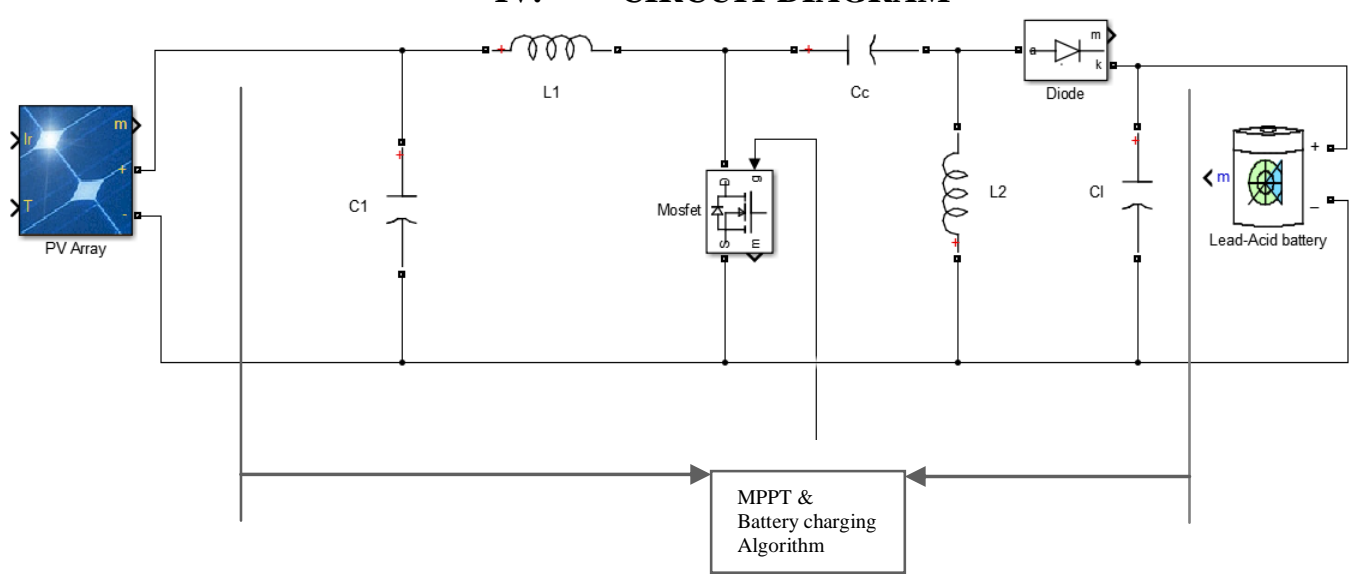

Fig.4: Circuit diagram of solar panel connecting battery via SEPIC.

The operation of SEPIC is dependent on the switching element, MOSFET which is operated by algorithm block. The PWM (pulse width modulation) gate pulses are generated by comparing carrier sawtooth wave with the reference voltage. This reference voltage is varied by algorithm block. Two algorithms are immersed in the algorithm block. One is Safe Battery charging algorithm which takes voltage and current details of battery to execute and other is MPPT algorithm which takes voltage and current details of the solar panel to execute. Both these algorithm change reference voltage accordingly and PWM gating pulses are generated.

Initially When MOSFET is ON inductor L1 is energized, when MOSFET is OFF inductor L1 transfers energy stored in it to coupling capacitor $\mathrm{Cc}$, in next cycle when MOSFET is turned ON inductor L1 gets energized along with it the charge stored in coupling capacitor is transferred to inductor L2 and diode will be in reverse bias. When MOSFET turns OFF the power stored in L1 gets transferred to $\mathrm{Cc}$ and diode gets forward biased the power from L2 is supplied to load through diode. 
Vol. 3, Special Issue 2, Month 2016

\section{SIMULATION RESULTS}
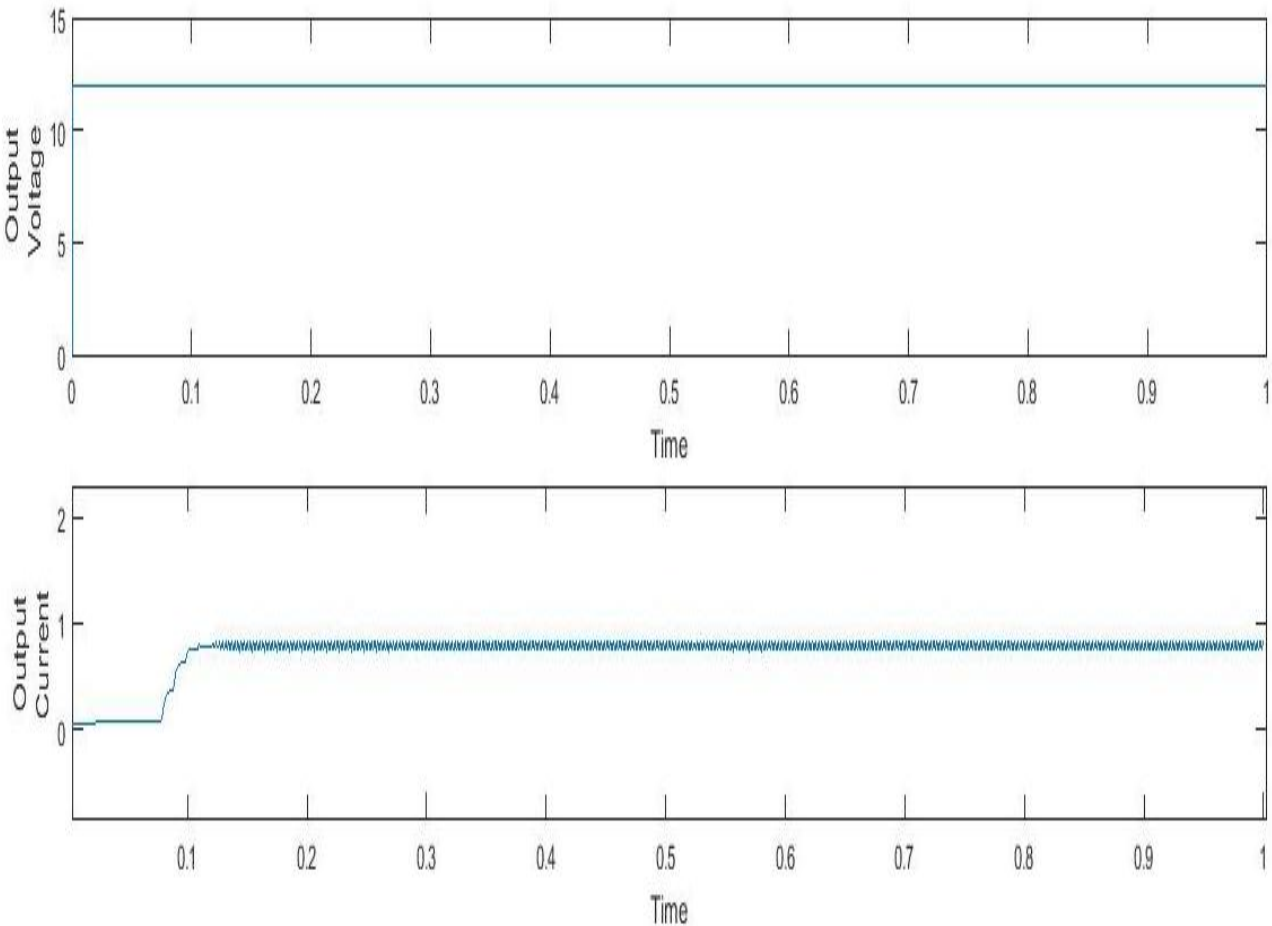

Fig.5: Simulation Output 1
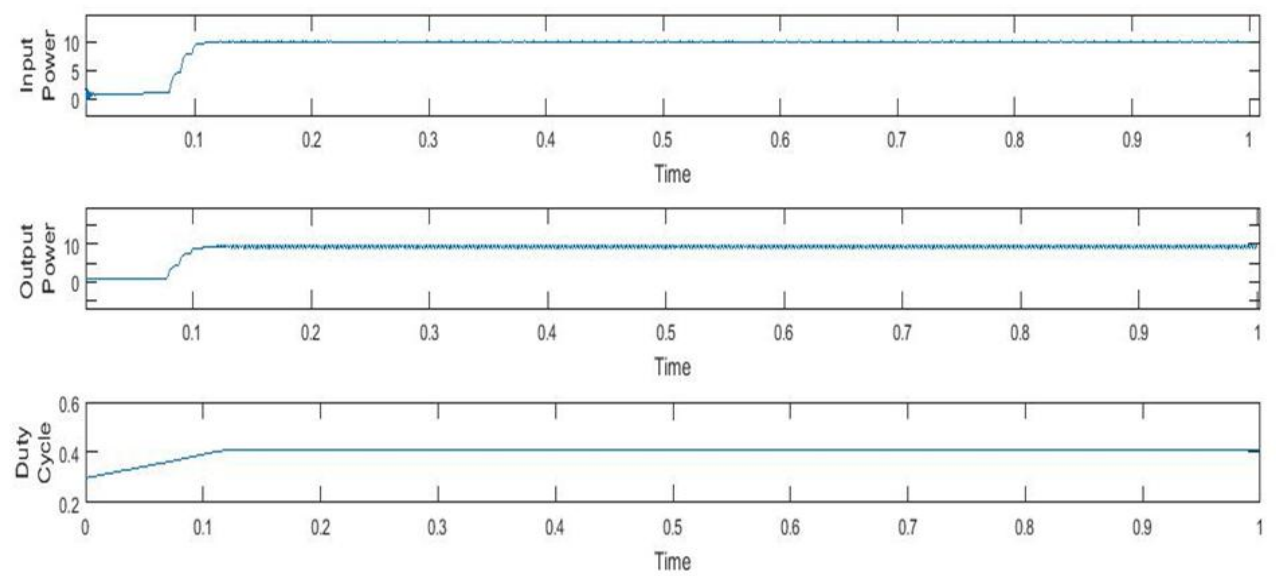

Fig 6: Simulation Output 2

\section{CONCLUSION}

In this paper battery charging algorithm and MPPT incremental algorithm is studied. It can be seen in the simulation results that output power follows input power and duty cycle is adjusted accordingly to track maximum power point.

\section{ACKNOWLEDGMENT}

I hereby thank my guide Mrs. Bharathi A Rao for her valuable guidance and moral support. I also wish to thank the head of the department and the staff members of electrical and electronics department, St. Joseph Engineering college for value able feedback.

\section{REFERENCES}

[1]. Jose Antonio Barros Vieira, alexander Manuel Mota "Maximum Power Point Tracker Applied in Batteries Charging with PV Panels" IEEE Transactions,2008.

[2]. Jose Antonio Barros Vieira, alexander Manuel Mota“Implementation of Stand-alone Photovoltaic Lighting System with MPPT Battery Charging and LED current control" ieee multi-conference on systems and control yokohama, japan, september 8-10, 2010

[3]. M.Kaouane, A.Boukhelifa and A.Cheriti "Design of a synchronous SEPIC DC-DC converter for stand-alone Photovoltaic system" proceeding of the IEEE $28^{\text {th }}$ Canadian conference on electrical and computer Engineering Halifax, Canada, May 3-6, 2015 